\title{
Bone Healing in Ovariectomized-rabbit Calvarial Defect with Tricalcium Phosphate Coated with Recombinant Human Bone Morphogenetic Protein-2 Genetically Engineered in Escherichia coli
}

\author{
Jung-Han Kim, Chang-Joo Kim, Sang-Hun Shin \\ Department of Oral and Maxillofacial Surgery, Pusan National University School of Dentistry
}

\begin{abstract}
Purpose: This study compares the bone formation ability of tricalcium phosphate (TCP) with and without recombinant human bone morphogenetic protein-2 (rhBMP-2) and assesses TCP as a carrier of rhBMP-2.

Methods: Bilateral round defects (diameter: $8.0 \mathrm{~mm}$ ) were formed in the cranium of eight New Zealand white rabbits. The defects were grafted with TCP only (control group) or with rhBMP-2-coated TCP (experimental group). The animals were sacrificed at 1st week, 2nd week, 4th week, and 8th week postoperatively; two rabbits sacrificed each time. The skulls were harvested and subjected to radiographic and histological examination.

Results: Radiologic evaluation showed faster bone remodeling in the experimental group than in the control group. Histologic evaluation (H\&E, Masson's trichrome stain) showed rapid bone formation, remodeling and calcification in the 1st and 2nd week in the experimental group. Immunohistochemical evaluation showed higher expression rate of osteoprotegerin, receptor activator of nuclear factor $\kappa \mathrm{B}$ ligand, and receptor activator of nuclear factor $\kappa \mathrm{B}$ in the experimental group at the 1st and 2 nd week than in the control group.

Conclusion: rhBMP-2 coated TCP resulted in rapid bone formation, remodeling, and calcification due to rhBMP-2's osteogenic effect. TCP performed properly as a carrier for rhBMP-2. Thus, the use of an rhBMP-2 coating on TCP had a synergic effect on bone healing and, especially, bone remodeling and maturation.
\end{abstract}

Key words: Recombinant human bone morphogenetic protein-2, Tricalcium phosphate, Bone regeneration

\section{Introduction}

Defects in the maxillofacial skeleton generally are reconstructed with autogenous bone grafts[1]. Although autogenous bone performs best, its supply is limited. Bone harvesting at donor sites, moreover, incurs surgical stress and complications such as pain, bleeding and postoperative infection. To obviate the need for graft harvesting with its accompanying morbidity, bone substitutes and bone production via bioengineering are much sought-after

RECEIVED January 13, 2014, REVISED February 3, 2014, ACCEPTED February 25, 2014

Correspondence to Sang-Hun Shin

Department of Oral and Maxillofacial Surgery, Pusan National University School of Dentistry

49 Busandaehak-ro, Mulgeum-eup, Yangsan 626-870, Korea

Tel: 82-55-360-5113, Fax: 82-55-360-5104, E-mail: ssh8080@pusan.ac.kr

Copyright (C) 2014 by The Korean Association of Maxillofacial Plastic and Reconstructive Surgeons. All rights reserved.

(c) This is an open access article distributed under the terms of the Creative Commons Attribution Non-Commercial License (http://creativecommons. org/licenses/ by-nc/3.0) which permits unrestricted non-commercial use, distribution, and reproduction in any medium, provided the original work is properly cited. 
alternatives. Ideally, bone grafts should be non-immunogenic and non-inflammatory, and should allow for rapid osteoinductivity, rapid osteoconductivity and rigid osteointegration[2,3].

Necessary for bone tissue formation at defect sites are osteogenic cells that induce it, a scaffold that can accommodate the proliferation and differentiation of cells at appropriate locations, and the osteoinductive growth factors that stimulate its differentiation induction. The osteoinductive growth factors include bone morphogenetic proteins (BMPs), transforming growth factors (TGF- $\beta$ ), insulin-like growth factor and others, among which BMPs are known to be the most effective[4-6]. BMPs, first noted by Urist[7] in 1965, have been investigated for their bone-growth-inducing properties. Specifically, BMPs can induce differentiation of mesenchymal cells and stem cells into osteoblasts and chondroblasts, as well as induce ectopic bone formation in soft tissue[8-10]. BMPs are also important in embryogenesis at bone fracture sites. BMPs induce new bone chiefly via the endochondral pathway. BMPs released from a carrier initially induce formation of cartilage tissue around that carrier, which tissue gradually is replaced by bone[11]. Happily, it is expected that therapeutic application of recombinant human BMP-2 (rhBMP-2) in bone generation and augmentation will become possible[12-14].

Tricalcium phosphate $\left(\mathrm{Ca}_{3}\left(\mathrm{PO}_{4}\right)_{2}\right.$; TCP), a synthetic, biodegradable bone-promoting and replacement biomaterial, has been extensively investigated for the repair of various shapes and sizes of bone defect caused by trauma, tumor resection or skeletal abnormalities, owing to its good biocompatibility and osteointegrative properties[15]. TCP is generally regarded as highly osteoconductive but not osteoinductive[16-20]. In the present study, we used TCP as a non-immunogenic, inorganic carrier for rhBMP-2, which has osteoinductive properties sufficient for realization of composite biomaterial. We studied osteoinduction in rabbit calvarial bone defects, comparing an experimental group treated with rhBMP-2-coated TCP with a control group (treated with TCP only). We compared the bone formation capability of TCP with and without rhBMP-2 and assessed TCP as an rhBMP-2 carrier.

\section{Materials and Methods}

\section{Animals and group design}

Eight New Zealand adult female rabbits older than 6 months, weighing between 2.5 and $3.5 \mathrm{~kg}$, were used in the study. The animals were housed individually in standard rabbit cages at an ambient temperature of $20^{\circ} \mathrm{C}$ under a 12/12 hour light/dark cycle. The animals had free access to drinking water and standard laboratory pellets.

All of the rabbits underwent an ovariectomy under general anesthesia (intramuscular Ketamine $\mathrm{HCl}[50 \mathrm{mg} / \mathrm{kg}$; $\operatorname{Ketalar}^{\circledR}$; Yuhan, Seoul, Korea] and Xylazine $[10 \mathrm{mg} / \mathrm{kg}$; Rumpun ${ }^{\circledR}$; Bayer Korea, Seoul, Korea]; mixture ratio: 5/1) and sterile conditions. After a healing period of 4 weeks, an operation was performed on the cranium. In preparation, the dorsal area of the cranium was shaved and the surgical field was prepared with iodine solution. A midline incision was performed on the skull, and the periosteum was reflected laterally, exposing the parietal bones. Two symmetrical, 8-mm-wide bone defects were formed using a round bur under constant irrigation. Special care was taken to avoid injury to the dura (Fig. 1).

The left defects (the experimental group) were grafted with rhBMP-2-coated TCP, and the right defects (the control group) with TCP only. After adequate hemostasis, the periosteum was closed with a 4-0 vicryl suture and the skin with a $4-0$ nylon suture. The animals were given $5 \mathrm{mg} / \mathrm{kg}$ gentamycin postoperatively to prevent infection. The postoperative courses were uneventful.

The rabbits were sacrificed at the 1st, 2nd, 4th, and 8th weeks postoperatively, two each time. The skulls were harvested and subjected to radiographic and histological examination. All of the experiments were conducted in accordance with the ethical committee of the Medical Research Institute of Dong-A University.

\section{Preparation of recombinant human bone morphogenetic protein-2-coated tricalcium phosphate}

TCP coated with rhBMP-2 (Cowellmedi Co., Busan, Korea) was employed as the bone grafting material. The rhBMP-2 was genetically engineered in Escherichia coli and 

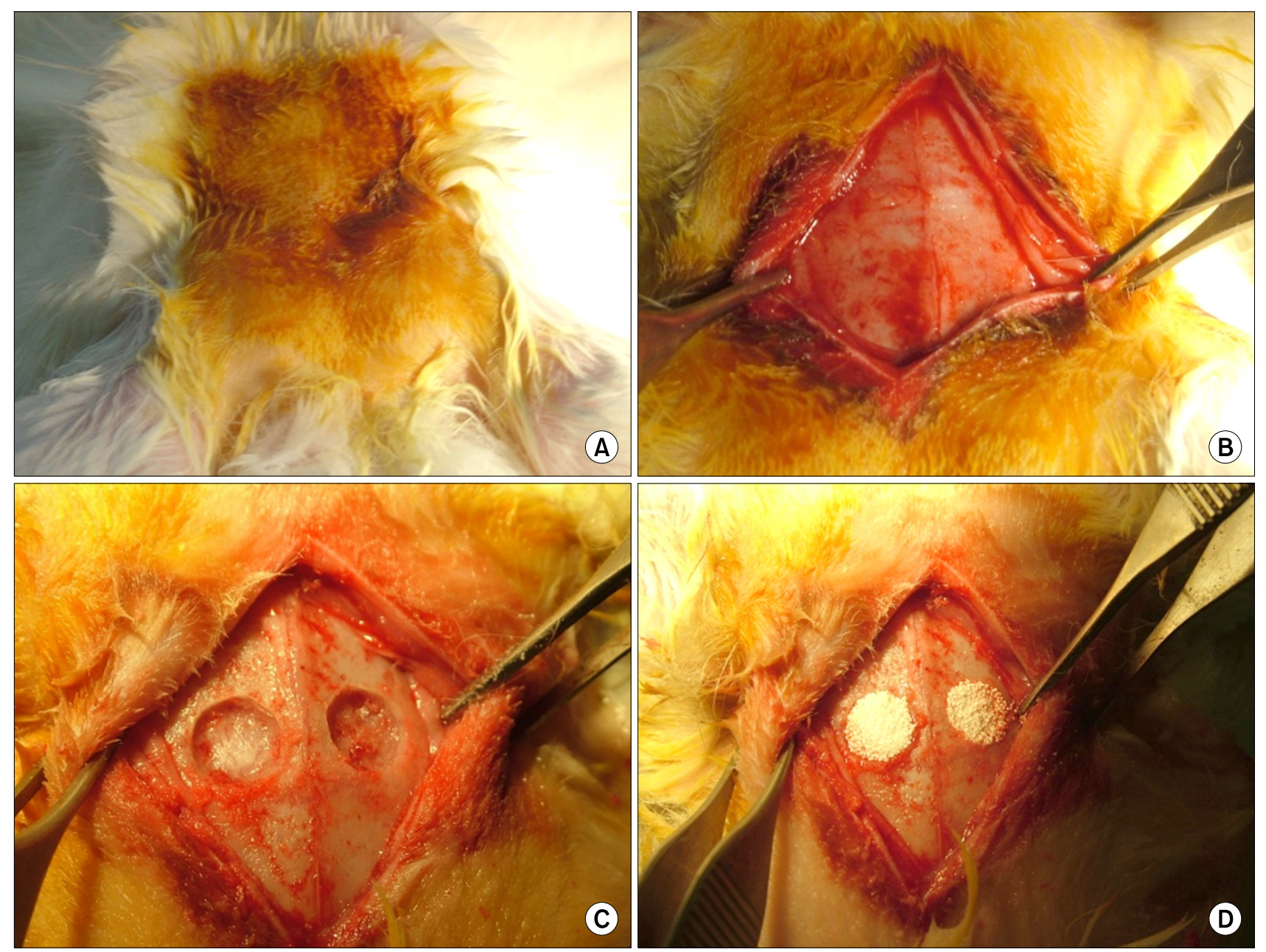

Fig. 1. (A) The surgical field was prepared with an iodine solution. (B) Dissection and elevation of periosteum. (C) 8 mm bony defect formation on the parietal bone lateral to the mid-sagittal suture. (D) Defect on left side was grafted with tricalcium phosphate (TCP) coated with recombinant human bone morphogenetic protein-2, and opposite side (right) was grafted with TCP only.

activated using high-BMP-2-expressing U2OS cells (human osteosarcoma cell line). The mature forms of rhBMP-2 were cloned from U2OS cells. The high density culture was performed and refined protein. Finally, dimerized rhBMP-2 was purified by affinity chromatography using a Heparin column. The rhBMP-2, in $0.1 \mathrm{mg} / \mathrm{mL}$ concentrations, was adsorbed onto the TCP by incubating the TCP for 24 hours.

\section{Micro-computed tomography analysis}

At each time point (1st week, 2nd week, 4th week, 8th week), the calvaria of two rabbits were scanned by micro-computed tomography ( $\mu \mathrm{CT}$; FLEX $^{\mathrm{TM}}$ for flatform $\mathrm{X}-\mathrm{O}^{\mathrm{TM}}$; GMI, Northridge, CA, USA) horizontally, coronally and sagittally for measurement of the bone mineral density (BMD) at the 1st, 2nd, 4th, and 8th weeks (Fig. 2). The BMD $(\mathrm{mg} / \mathrm{mL})$ was taken within the cylindrical region of interest (ROI), that is, the defect site, which showed a higher radiopacity on the $\mu \mathrm{CT}$ view.

\section{Histology}

Each specimen was fixed in a 10\% formaldehyde solution, decalcified in formic acid for 48 hours, and embedded in paraffin. Serial cross-sections $(5 \mu \mathrm{m})$ were cut through the large diameter of the defect and stained with hematoxylin-eosin (H\&E) and Masson's trichrome, with which the cellular reaction and bone formation were evaluated. The slides were photographed using an image analysis system (Axiovision 4.3, Carl Zeiss, Jena, Germany).

\section{Immunohistochemistry}

Additional sections were mounted on glass slides for immunohistochemical analysis of the expressions of osteo- 

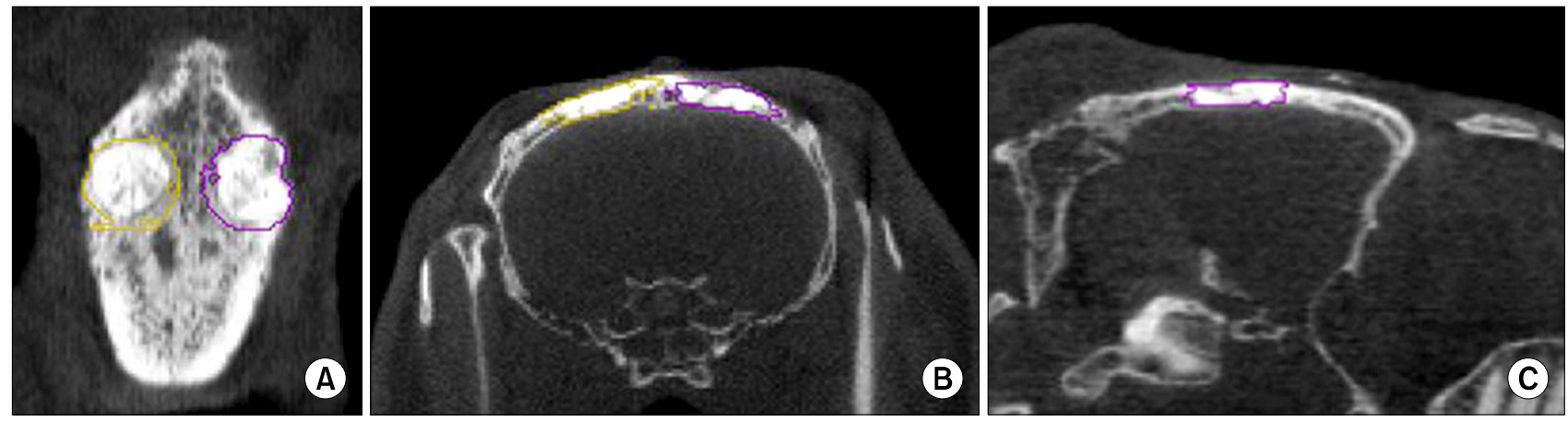

Fig. 2. Micro-computed tomography analysis. (A) Horizontal view. (B) Coronal view. (C) Sagittal view.
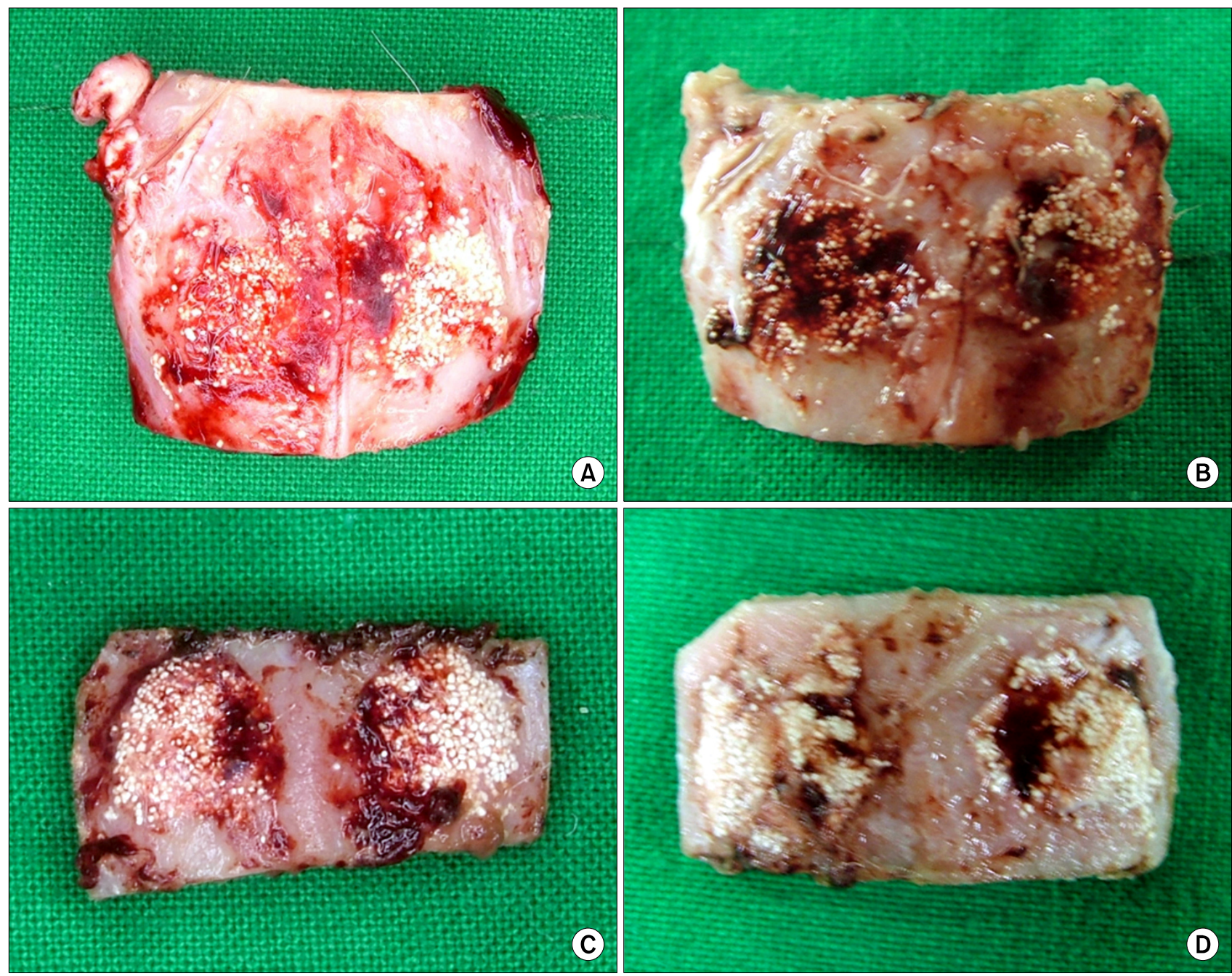

Fig. 3. Gross appearance. Defect on left side was grafted with tricalcium phosphate (TCP) coated with recombinant human bone morphogenetic protein-2, and opposite side (right) was grafted with TCP only. (A) One week after surgery. (B) Two weeks after surgery. (C) Four weeks after surgery. (D) Eight weeks after surgery.

protegerin (OPG), the receptor activator of nuclear factor $\kappa \mathrm{B}$ ligand (RANKL), and the receptor activator of nuclear factor $\kappa \mathrm{B}$ (RANK) in the rabbit calvarial defects. These regulate osteoclast formation, differentiation, and activity. The slides were coated with $4 \mu \mathrm{m}$ on the dried slice, and maintained at $60^{\circ} \mathrm{C}$ in an oven for an hour. After re- 
moval of the paraffin by washing four times with xylene for five minutes, the slides were washed with distilled water after hydration with alcohol. The slides were then washed three times for 3 minutes with buffer solution. To remove the intrinsic peroxide, the sample was reacted with $0.3 \%$ $\mathrm{H}_{2} \mathrm{O}_{2}$ solution. Subsequently it was washed 4 times with buffer solution to inhibit reactions within the tissue after reacting with blocking serum (Goat Immunocruz staining system; Santa Cruz Biotechnology Inc., Santa Cruz, CA, USA) for an hour and reacting overnight with a dilution (OPG 1:120, RANKL 1:40, RANK 1:90) of each primary antibody, OPG (sc-8468; Santa Cruz Biotechnology Inc.), RANK (sc-7625; Santa Cruz Biotechnology Inc.), RANKL (sc-7692; Santa Cruz Biotechnology Inc.). The sample was washed again with buffer solution, reacted with a secondary $\mathrm{Ab}$ labeled Biotin for an hour, washed four times more with buffer solution, and reacted with the enzyme conjugate streptavidin (Goat Immunocruz staining system; Santa Cruz Biotechnology Inc.) for an hour.

The immunohistochemical analysis was performed individually by two examiners blind to the treatment conditions. The relative staining intensity was assessed for each antibody. The samples were scored as follows: - = no immunoreactivity; + = weak but visible staining; ++ $=$ moderate staining; $+++=$ strong staining intensity.

\section{Results}

\section{Clinical observation}

All of the animals recovered from the operation and healed without complications. Both the TCP and the rhBMP-2-coated TCP were well adapted into critical bone defects. In the experimental group, the graft material was rigid and well osseointegrated (Fig. 3) at the 1st and 2nd weeks compared with the control group.

\section{Micro-computed tomography analysis}

The results of the BMD $(\mathrm{mg} / \mathrm{mL})$ measurement within the ROI for each group are listed in Table 1. In both groups, the BMD value increased significantly from the 1st to the 8th week. The defects grafted with rhBMP-2-coated TCP; however, had higher BMD values than those grafted with TCP only. The mean total BMD in the experimental group $(246.196 \mathrm{mg} / \mathrm{mL})$ was higher than in the control group $(221.642 \mathrm{mg} / \mathrm{mL})$. The standard deviation of BMD values was 47.481 in the control group and 30.438 in the experimental group. The mean BMD difference (28.242 $\mathrm{mg} / \mathrm{mL}$ ) between the two groups through the 1st, 2nd and 4th weeks was higher than that $(13.49 \mathrm{mg} / \mathrm{mL})$ at the 8 th week (Table 1).

\section{Histological findings}

\section{1) $\mathrm{H} \& \mathrm{E}$ staining}

By the 1st week post-grafting, the control group had not formed bone, while the experimental group showed aspects of partial bone formation. By the 2nd weeks, bone formation within the control group was observed, along with advanced bone formation and mineralization in the experimental group. By the 4th weeks, both groups showed more advanced calcification, and by the 8th week, both presented complete calcification (Fig. 4).

\section{2) Masson's trichrome staining}

Both groups in the 1st week showed a dark blue color indicating collagen and bone formation within the TCP, though the experimental group, in the 1st and 2nd weeks, more strongly. Both groups by the 4 th weeks showed continuous activation of bone remodeling. Further, both groups manifested more specific aspects in the 8th weeks, specifically collagen and reddish-colored matured bone (Fig. 5).

Table 1. Bone mineral density $(\mathrm{mg} / \mathrm{mL})$ in critical bone defects

\begin{tabular}{|c|c|c|c|c|}
\hline \multirow{2}{*}{ Post-graft period } & \multicolumn{2}{|c|}{ Case I } & \multicolumn{2}{|c|}{ Case II } \\
\hline & Control site & Experimental site & Control site & Experimental site \\
\hline 1st week & 205.398 & 222.454 & 203.539 & 227.261 \\
\hline 2nd week & 157.481 & 210.760 & 221.389 & 240.168 \\
\hline 4th week & 167.580 & 208.584 & 267.579 & 283.187 \\
\hline 8th week & 287.879 & 284.630 & 262.294 & 292.521 \\
\hline
\end{tabular}



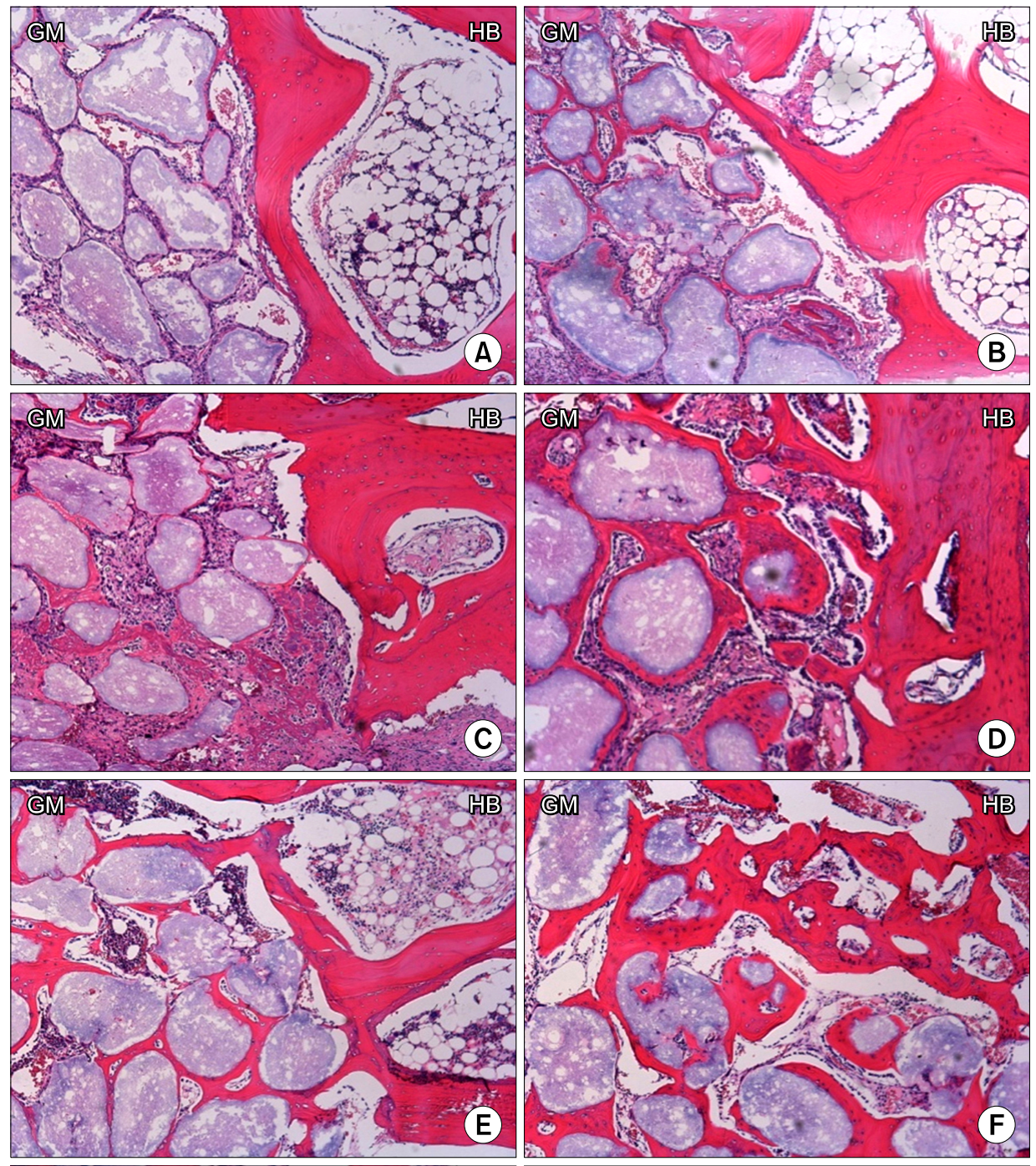

Fig. 4. Histologic photograph (H\&E, $\times 100$ ). (A) Microphotograph at 1
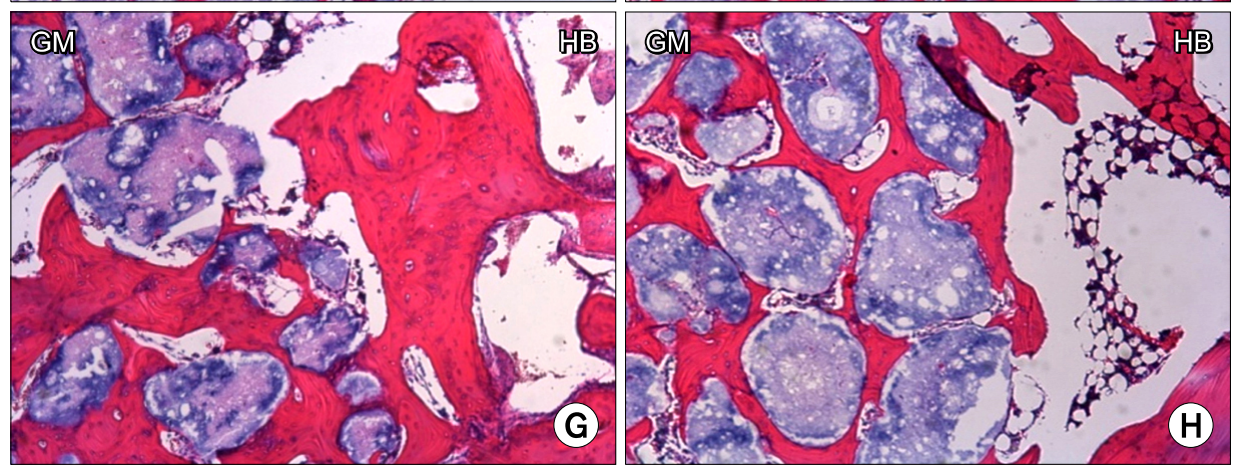
week after graft in control site. (B) Microphotograph at 1 week after graft in experimental site. (C) Microphotograph at 2 weeks after graft in control site. (D) Microphotograph at 2 weeks after graft in experimental site. (E) Microphotograph at 4 weeks after graft in control site. (F) Microphotograph at 4 weeks after graft in experimental site. (G) Microphotograph at 8 weeks after graft in control site. (H) Microphotograph at 8 weeks after graft in experimental site. GM, graft material; $\mathrm{HB}$, host bone.

\section{Immunohistochemical findings}

\section{1) Osteoprotegerin}

More specific OPG expression was observed in the experimental group than in the control group up to 2 weeks after grafting. Expression increased in both groups from the 1 st to the 2 nd weeks. The expression period was one week earlier in the experimental group. Expression was similar in both groups in the 4th week (Table 2, Fig. 6).

2) Receptor activator of nuclear factor $\kappa \mathrm{B}$ ligand RANKL expression, related to osteoclast activity, was observed within the grafting material in both the experimental and control groups. The 1st and 2nd weeks after grafting, 

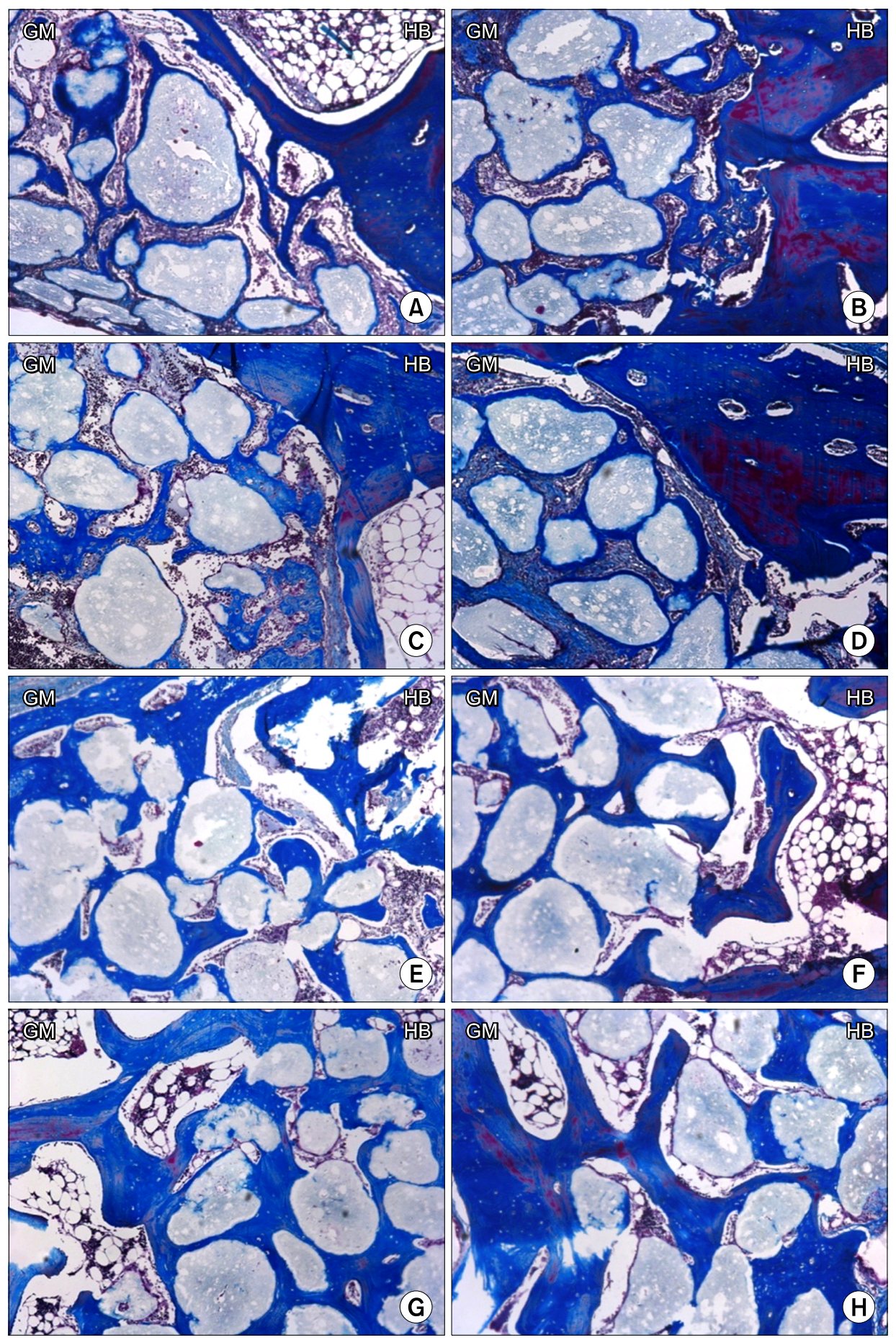

Fig. 5. Histologic photograph (Masson's trichrome stain, $\times 100$ ). (A) Microphotograph at 1 week after graft in control site. (B) Microphotograph at 1 week after graft in experimental site. (C) Microphotograph at 2 weeks after graft in control site. (D) Microphotograph at 2 weeks after graft in experimental site. (E) Microphotograph at 4 weeks after graft in control site. (F) Microphotograph at 4 weeks after graft in experimental site. (G) Microphotograph at 8 weeks after graft in control site. (H) Microphotograph at 8 weeks after graft in experimental site. GM, graft material; $\mathrm{HB}$, host bone.

a specific increment of RANKL expression was observed in the experimental group; after the 4th and 8th weeks, a similar expression developed in the control group (Table 3, Fig. 7).

3) Receptor activator of nuclear factor $\kappa \mathrm{B}$

The results for RANK expression were similar to those for OPG and RANKL. At the 1st and 2nd weeks after grafting, the experimental group showed more specific RANKL expression than the control group. The levels decreased by the 4th and 8th weeks, showing similar expression aspects between the two groups (Table 4, Fig. 8). The experimental group's expression of OPG, RANKL, and RANK were higher in the 1 st and 2nd weeks but decreased to 
Table 2. Osteoprotegerin expression after tricalcium phosphate graft

\begin{tabular}{ccc}
\hline Post-graft period & Control group & Experimental group \\
\hline 1st week & ++ & $++/+++$ \\
2nd week & $+/++$ & ++ \\
4th week & ++ & ++ \\
8th week & - & + \\
\hline
\end{tabular}

-, no immunoreactivity; +, weak but visible staining; ++, moderate staining; +++, strong staining intensity. the level of the control group in the 4th and 8th weeks.

\section{Discussion}

A successful bone replacement material must be biocompatible, biodegradable and osteoconductive so as to attract cells to the defect site and promote the formation
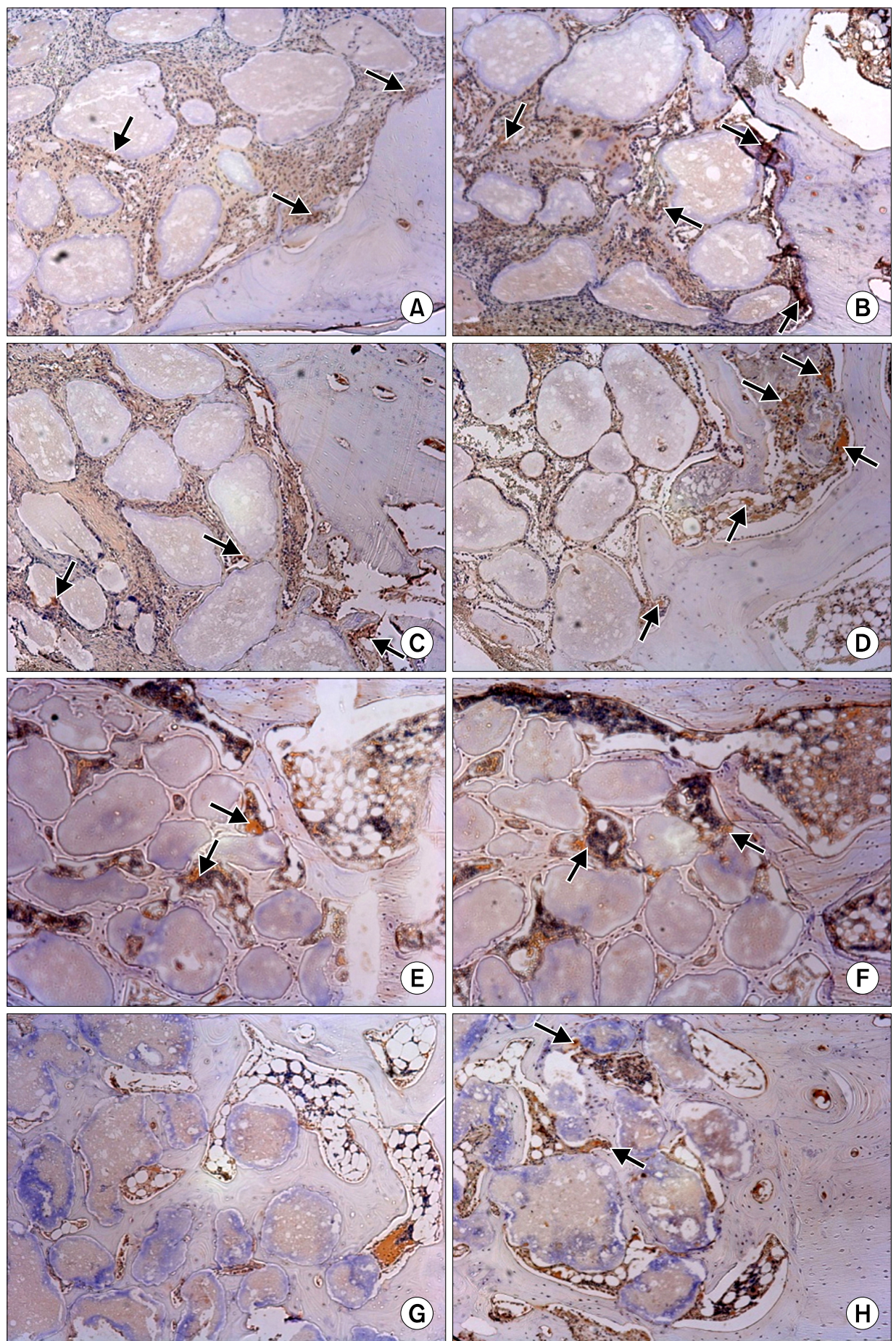

(H)
Fig. 6. Osteoprotegerin (OPG) antibody reaction $(\times 100)$. (A) Regenerating bone at 1 week after graft in control site. (B) Regenerating bone at 1 week after graft in experimental site. (C) Regenerating bone at 2 weeks after graft in control site. (D) Regenerating bone at 2 weeks after graft in experimental site. (E) Regenerating bone at 4 weeks after graft in control site. (F) Regenerating bone at 4 weeks after graft in experimental site. (G) Regenerating bone at 8 weeks after graft in control site. (H) Regenerating bone at 8 weeks after graft in experimental site. Black arrows indicate OPG antibody reaction. OPG positive signals appear as a red color. 
Table 3. Receptor activator of nuclear factor $\kappa$ B ligand expression after tricalcium phosphate graft

\begin{tabular}{ccc}
\hline Post-graft period & Control group & Experimental group \\
\hline 1 st week & ++ & +++ \\
2nd week & ++ & $++/+++$ \\
4th week & $+/++$ & $+/++$ \\
8th week & $-/+$ & $-/+$ \\
\hline
\end{tabular}

-, no immunoreactivity; +, weak but visible staining; ++, moderate staining; +++, strong staining intensity. of new bone. The most direct approach to successful development of artificial bone is to produce a material having a composition similar to that of natural bone. TCP, composed of calcium and phosphate ions, the same ions that make up the bulk of natural bone mineral, is widely utilized to increase the osteoconductive characteristics of bone replacement therapies. However, TCP does not have os-
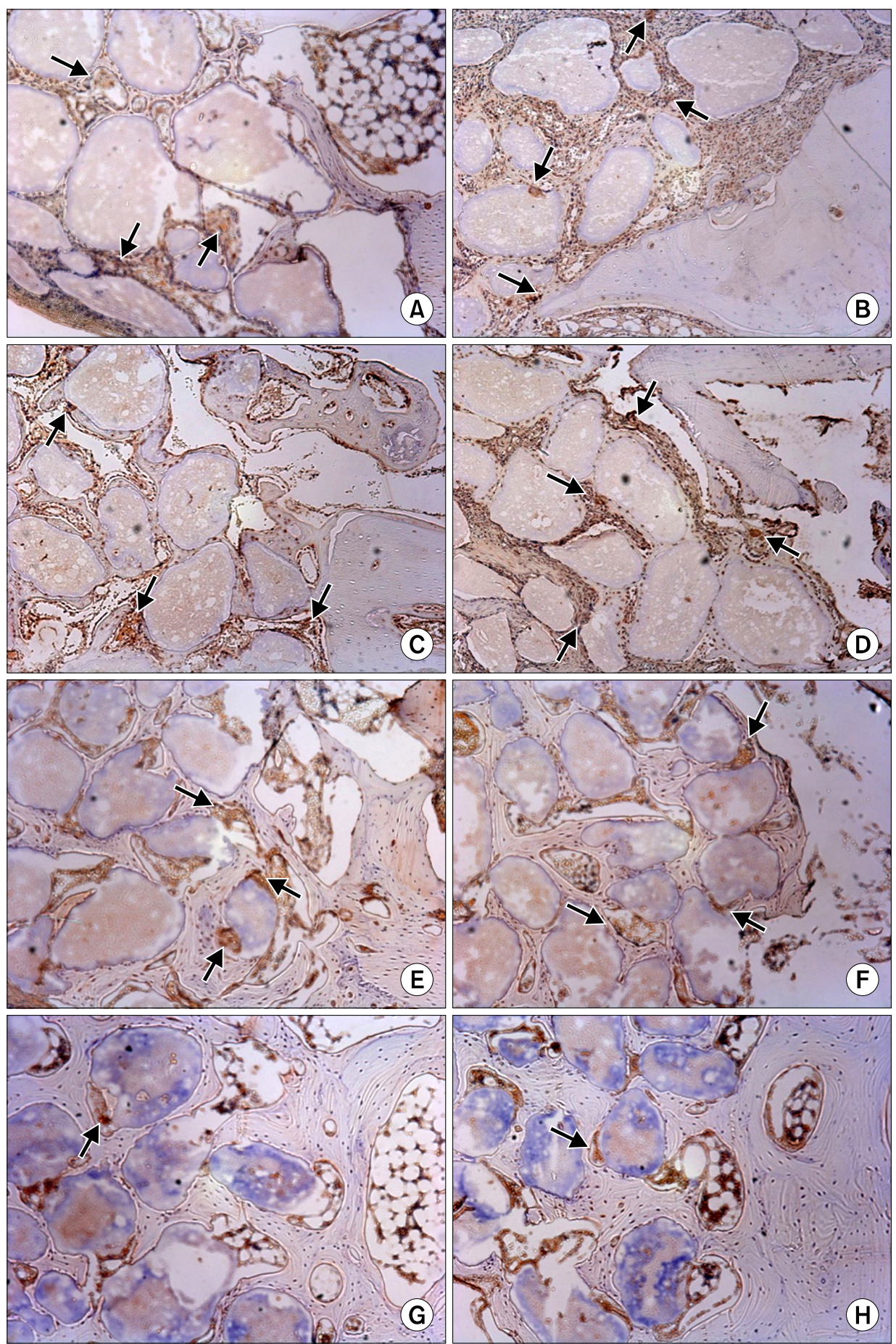

Fig. 7. Receptor activator of nuclear factor $\kappa$ B ligand (RANKL) antibody reaction $(\times 100)$. (A) Regenerating bone at 1 week after graft in control site. (B) Regenerating bone at 1 week after graft in experimental site. (C) Regenerating bone at 2 weeks after graft in control site. (D) Regenerating bone at 2 weeks after graft in experimental site. (E) Regenerating bone at 4 weeks after graft in control site. (F) Regenerating bone at 4 weeks after graft in experimental site. (G) Regenerating bone at 8 weeks after graft in control site. $(\mathrm{H})$ Regenerating bone at 8 weeks after graft in experimental site. Black arrows indicate RANKL antibody reaction. RANKL positive signals appear as a red color. 
Table 4. Receptor activator of nuclear factor $\kappa \mathrm{B}$ expression after tricalcium phosphate graft

\begin{tabular}{ccc}
\hline Post-graft period & Control group & Experimental group \\
\hline 1 st week & ++ & +++ \\
2nd week & $+/++$ & +++ \\
4th week & + & + \\
8th week & $-/+$ & $-/+$ \\
\hline
\end{tabular}

-, no immunoreactivity; + , weak but visible staining; ++ , moderate staining; +++, strong staining intensity. teoinductive properties. In the present study, TCP was coated with rhBMP-2, giving it osteoconductive properties.

BMPs are members of the TGF- $\beta$ super-family, a highly conserved group of cytokines with widespread expression in tissues and a variety of functions in embryology, the development stage. There is convincing evidence that BMPs are powerful inducers of osteoblast differentiation
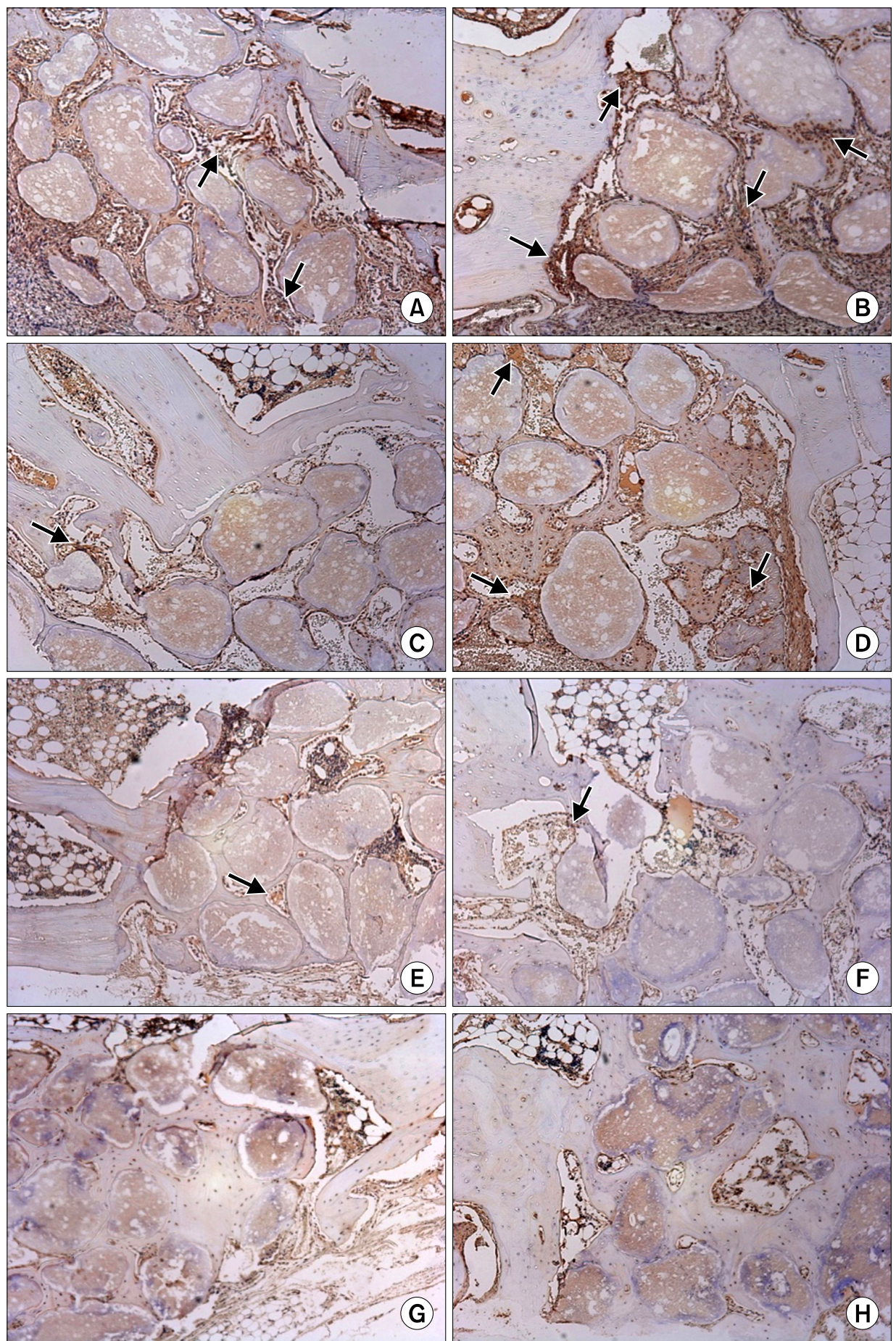

Fig. 8. Receptor activator of nuclear factor $\kappa$ B (RANK) antibody reaction $(\times 100)$. (A) Regenerating bone at 1 week after graft in control site. (B) Regenerating bone at 1 week after graft in experimental site. (C) Regenerating bone at 2 weeks after graft in control site. (D) Regenerating bone at 2 weeks after graft in experimental site. (E) Regenerating bone at 4 weeks after graft in control site. (F) Regenerating bone at 4 weeks after graft in experimental site. (G) Regenerating bone at 8 weeks after graft in control site. $(\mathrm{H})$ Regenerating bone at 8 weeks after graft in experimental site. Black arrows indicate RANK antibody reaction. RANK positive signals appear as a red color. 
and bone formation. Over 20 different isoforms of BMPs have been identified; BMP-2, -4 and -7 are thought to be most important in the skeletal system[21,22]. Higuchi et al.[23], using rat mandible through-and-through bone defects, observed a larger quantity of new bone in the experimental group (rhBMP-2 $0.1 \mu \mathrm{g} / \mu \mathrm{L}$ with a polylactic acid-polyglycolic acid copolmer/gelatin sponge carrier) than in the control group (the same carrier without rhBMP-2). Matin et al.[24] observed that rhBMP-2 prevented residual ridge resorption after tooth extraction. They found larger numbers of proliferating cells and densely populated differentiating mesenchyme cells, as well as a greater total bone area and increased bone height on the rhBMP-2. This finding replicates others, that of rapid bone formation and mineralization in the experimental group due to the osteogenic capability of rhBMP-2.

Various inorganic carriers are used as BMP delivery systems[25-28]. The ideal scaffold material requires specific mechanical properties, biocompatibility, biodegradability, absence of allergic reaction, disease transmission, delivery of the osteoinductive factor, gross architecture, shaping, clinical handling and regulatory issues. No currently available scaffold material meets all of these demands. Misch and Dietsh[29] argued that TCP, despite its porosity, is appropriate for mixed use in enhancing the maneuverability of osteogenetic substances such as BMPs, or for use in osteoconductive grafting materials, due to its high stability and abrasion resistance.

We selected TCP as the rhBMP-2 carrier because it is the most stable and appropriate material from the bone formation standpoint. We genetically engineered rhBMP-2 in $E$. coli and adsorbed it onto the TCP in a $100 \mu \mathrm{g} / \mathrm{mL}$ concentration. Pang et al.[30] reported of rhBMP-4 combined with adsorbent collagen sponge or $\beta$-TCP, within the selected rhBMP-4 dose range $(0.025 \mathrm{mg} / \mathrm{mL}, 0.05$ $\mathrm{mg} / \mathrm{mL}$ ), there appeared to be no meaningful differences in bone formation. Other workers, applying rhBMP-2 concentration of $10,50,100,200 \mathrm{mg} / \mathrm{L}$, found that proliferation and differentiation of mesenchymal stem cell depends on concentration. Particularly, osteoblast differentiation accelerated at $100 \mathrm{mg} / \mathrm{L}, 200 \mathrm{mg} / \mathrm{L}[31]$. We selected $0.1 \mathrm{mg} / \mathrm{mL}$ concentration of rhBMP-2 for the experiment. However, studies on the proper rhBMP-2 concentration with carrier TCP are lacking, as are those on rhBMP-2-release periods.
Both calcium deficiency and ovariectomy can induce osteoporosis experimentally. However, while calcium deficiency does not seem to impair bone healing, the effect of ovariectomy is not known[32]. Ovariectomy decreases bone density in rabbits[33]. Therefore, we performed ovariectomies on rabbits to reduce BMD and induce osteoporosis, and used TCP, consisting of calcium and phosphate ions, to supply calcium to low-calcium bone.

Recent research identifies OPG, RANKL and RANK as factors affecting bone formation and remodeling. In the case of OPG increment, pre-osteoclasts are inhibited from activating or differentiating. Also, osteoclast necrosis increases and bone resorption decreases. Bone formation, then, predominates. RANKL increment produces an opposite effect, activating and differentiating pre-osteoclasts, so that bone resorption increases. RANKL induces many intercellular reactions by bonding to RANK in pre-osteoclasts and osteoclasts[34-36]. Bone resorption and osteogenesis increments are required for active bone remodeling. Therefore, high expression levels of OPG, RANKL and RANK indicate active bone remodeling. rhBMP-2 promotes expression of cyclooxygenase- 2 and the osteoclast differentiation factor in osteoblast-like cells, regulating osteoclastogenesis[37]. The mitogenic, chemotactic and differentiating effect of BMPs may help to mediate coupling of bone formation to resorption. We can determine changes of bone regeneration rates by closely monitoring the changes of OPG, RANKL and RANK.

In this study, we grafted rhBMP-2-coated TCP and uncoated TCP onto left- and right-side defects to the skull of ovariectomized rabbits and evaluated the extents of bone formation and remodeling in radiological, $\mu \mathrm{CT}$, histological and immunohistochemical analyses (OPG, RANKL, RANK).

In the $\mu \mathrm{CT}$ analysis results, the BMP group showed faster bone formation and remodeling than the control group in the 1st and 2nd weeks. Results were the same for the histological and immunohistochemical evaluations. Collagen formation, early calcification, and mineralization occurred earlier in the rhBMP-2-coated TCP. OPG, RANKL, and RANK expressed at higher rates in the experimental group in the 1st and 2nd weeks. We can assume from these findings that vigorous bone remodeling occurs as osteoclast differentiation is accelerated by rhBMP-2 at the 
early stages. By the 4th and 8th weeks, there were no significant histological or immunohistochemical differences, because the graft material had sufficiently matured in both groups. In summation, TCP is crucial as the rhBMP-2 carrier, enabling the latter to effect bone formation, remodeling, and mineralization at the early stages.

\section{Conclusion}

In this study, we grafted either rhBMP-2-coated TCP or TCP only onto calvaria defects in ovariectomized rabbits and evaluated the extents of bone formation and remodeling.

1. In the radiological results, bone remodeled faster in the experimental group than the control group. The BMD estimation by $\mu \mathrm{CT}$ indicated especially high values for the experimental group at the 1st, 2nd, and 4th weeks. However, there was no significant difference by the 8th week.

2. In the histological results (H\&E, Masson's Trichrome stain), bone formed rapidly in the experimental group, with remodeling and calcification in the 1st and 2nd weeks. However, there was no significant difference between the experimental and control groups in the 4th and 8th weeks.

3. In the immunohistochemical results, the OPG, RANKL, and RANK all expressed at higher rates in the experimental group at the 1st and 2nd weeks than the control group. This implies that osteoblasts and osteoclasts are more active at the early stages.

Overall, rhBMP-2-coated TCP led to rapid bone formation, remodeling, and calcification, owing to rhBMP-2's osteogenic effect. TCP performed properly as a carrier for rhBMP-2. The use of rhBMP-2 coated TCP had a synergic effect on bone healing, and especially, bone remodeling and maturation. All of these findings suggest strongly that rhBMP-2-coated TCP is a promising clinical application advance in maxillofacial surgery for critical size defects.

\section{References}

1. Bassett CA, Herrmann I. Influence of oxygen concentration and mechanical factors on differentiation of connective tissues in vitro. Nature 1961;190:460-1.

2. Goldberg VM, Stevenson S. Natural history of autografts and allografts. Clin Orthop Relat Res 1987;(225):7-16.

3. Okubo Y, Bessho K, Fujimura K, et al. Osteoinduction by recombinant human bone morphogenetic protein-2 at intramuscular, intermuscular, subcutaneous and intrafatty sites. Int J Oral Maxillofac Surg 2000;29:62-6.

4. Wozney JM, Rosen V, Celeste AJ, et al. Novel regulators of bone formation: molecular clones and activities. Science 1988; 242:1528-34.

5. Knaus P, Sebald W. Cooperativity of binding epitopes and receptor chains in the BMP/TGFbeta superfamily. Biol Chem 2001;382:1189-95.

6. Chen D, Zhao M, Mundy GR. Bone morphogenetic proteins. Growth Factors 2004;22:233-41.

7. Urist MR. Bone: formation by autoinduction. Science 1965; 150:893-9.

8. Kirker-Head CA. Potential applications and delivery strategies for bone morphogenetic proteins. Adv Drug Deliv Rev 2000;43:65-92.

9. Murata M, Inoue M, Arisue M, Kuboki Y, Nagai N. Carrierdependency of cellular differentiation induced by bone morphogenetic protein in ectopic sites. Int J Oral Maxillofac Surg 1998;27:391-6.

10. Nagai N, Qin CL, Nagatsuka H, Inoue M, Ishiwari Y. Age effects on ectopic bone formation induced by purified bone morphogenetic protein. Int J Oral Maxillofac Surg 1999;28: 143-50.

11. Kamakura S, Sasano Y, Homma H, Suzuki O, Kagayama M, Motegi K. Implantation of octacalcium phosphate nucleates isolated bone formation in rat skull defects. Oral Dis 2001;7: 259-65.

12. Boyne PJ, Marx RE, Nevins M, et al. A feasibility study evaluating rhBMP-2/absorbable collagen sponge for maxillary sinus floor augmentation. Int J Periodontic Restor Dent 1997; $17: 11-25$.

13. Kenley R, Marden L, Turek T, Jin L, Ron E, Hollinger JO. Osseous regeneration in the rat calvarium using novel delivery systems for recombinant human bone morphogenetic protein-2 (rhBMP-2). J Biomed Mater Res 1994;28:1139-47.

14. Yasko AW, Lane JM, Fellinger EJ, Rosen V, Wozney JM, Wang EA. The healing of segmental bone defects, induced by recombinant human bone morphogenetic protein (rhBMP-2). A radiographic, histological, and biomechanical study in rats. J Bone Joint Surg Am 1992;74:659-70.

15. Ogose A, Kondo N, Umezu H, et al. Histological assessment in grafts of highly purified beta-tricalcium phosphate (OSferion) in human bones. Biomaterials 2006;27:1542-9.

16. Damien CJ, Parsons JR. Bone graft and bone graft substitutes: a review of current technology and applications. J Appl Biomater 1991;2:187-208.

17. Hollinger JO, Brekke J, Gruskin E, Lee D. Role of bone substitutes. Clin Orthop Relat Res 1996;(324):55-65.

18. Ohgushi H, Goldberg VM, Caplan AI. Heterotopic osteogenesis in porous ceramics induced by marrow cells. J Orthop Res 1989;7:568-78.

19. Ohgushi H, Okumura M, Tamai S, Shors EC, Caplan AI. Marrow cell induced osteogenesis in porous hydroxyapatite and tricalcium phosphate: a comparative histomorphometric study of ectopic bone formation. J Biomed Mater Res 1990;24: 1563-70.

20. St John KR, Zardiackas LD, Terry RC, Teasdall RD, Cooke SE, Mitias HM. Histological and electron microscopic analy- 
sis of tissue response to synthetic composite bone graft in the canine. J Appl Biomater 1995;6:89-97.

21. Asahina I, Sampath TK, Hauschka PV. Human osteogenic protein-1 induces chondroblastic, osteoblastic, and/or adipocytic differentiation of clonal murine target cells. Exp Cell Res 1996;222:38-47.

22. Hughes FJ, Collyer J, Stanfield M, Goodman SA. The effects of bone morphogenetic protein-2, -4 , and -6 on differentiation of rat osteoblast cells in vitro. Endocrinology 1995;136:2671-7.

23. Higuchi T, Kinoshita A, Takahashi K, Oda S, Ishikawa I. Bone regeneration by recombinant human bone morphogenetic protein-2 in rat mandibular defects. An experimental model of defect filling. J Periodontol 1999;70:1026-31.

24. Matin K, Senpuku H, Hanada N, Ozawa H, Ejiri S. Bone regeneration by recombinant human bone morphogenetic protein-2 around immediate implants: a pilot study in rats. Int J Oral Maxillofac Implants 2003;18:211-7.

25. Kuboki Y, Saito T, Murata M, et al. Two distinctive BMP-carriers induce zonal chondrogenesis and membranous ossification, respectively; geometrical factors of matrices for celldifferentiation. Connect Tissue Res 1995;32:219-26.

26. Ripamonti U, Ma S, Reddi AH. The critical role of geometry of porous hydroxyapatite delivery system in induction of bone by osteogenin, a bone morphogenetic protein. Matrix 1992;12:202-12.

27. Urist MR, Lietze A, Dawson E. Beta-tricalcium phosphate delivery system for bone morphogenetic protein. Clin Orthop Relat Res 1984;(187):277-80.

28. Viljanen VV, Gao TJ, Lindholm TC, Lindholm TS, Kommonen B. Xenogeneic moose (Alces alces) bone morphogenetic protein (mBMP)-induced repair of critical-size skull defects in sheep. Int J Oral Maxillofac Surg 1996;25:217-22.
29. Misch CE, Dietsh F. Bone-grafting materials in implant dentistry. Implant Dent 1993;2:158-67.

30. Pang EK, Im SU, Kim CS, et al. Effect of recombinant human bone morphogenetic protein- 4 dose on bone formation in a rat calvarial defect model. J Periodontol 2004;75:1364-70.

31. Yang X, Fang J, Luo Y. Effects of recombinant human bone morphogenetic protein 2 and osteogenic agents on proliferation and differentiation of rat mesenchymal stem cells. Zhongguo Xiu Fu Chong Jian Wai Ke Za Zhi 2007;21:140-4.

32. Lundgren S, Rosenquist JB. Short term bone healing in calcium deficiency osteopenia and disuse osteopenia: experimental studies in adult rats. Scand J Dent Res 1992;100: 337-9.

33. Cao T, Shirota T, Yamazaki M, Ohno K, Michi KI. Bone mineral density in mandibles of ovariectomized rabbits. Clin Oral Implants Res 2001;12:604-8.

34. Kwan Tat S, Padrines M, Théoleyre S, Heymann D, Fortun Y. IL-6, RANKL, TNF-alpha/IL-1: interrelations in bone resorption pathophysiology. Cytokine Growth Factor Rev 2004; 15:49-60

35. Theoleyre S, Wittrant Y, Tat SK, Fortun Y, Redini F, Heymann D. The molecular triad OPG/RANK/RANKL: involvement in the orchestration of pathophysiological bone remodeling. Cytokine Growth Factor Rev 2004;15:457-75.

36. Boyle WJ, Simonet WS, Lacey DL. Osteoclast differentiation and activation. Nature 2003;423:337-42.

37. Koide M, Murase Y, Yamato K, Noguchi T, Okahashi N, Nishihara T. Bone morphogenetic protein-2 enhances osteoclast formation mediated by interleukin-1alpha through upregulation of osteoclast differentiation factor and cyclooxygenase-2. Biochem Biophys Res Commun 1999;259: 97-102. 